\title{
A Theory of Reference Service
}

Library literature has presented very few papers on reference theory. Historically, much of the literature on the subject concerned such rudimentary efforts at quantification as urging maximum, minimum, or moderate levels of reference service. The present author contends that reference service is the entire congeries of library activities that aid the flow of needed information to the user.

F Frofer a considenabe time the library profession has concerned itself over the issue of whether or not there is a theoretical basis for librarianship, and if so what is it? This unresolved question has left library science suspect. Indeed, it has then led to the further query, "What is scientific about library science?" a moot question.

While the profession as a whole worries about this conceptual foundation, the same syndrome exists among reference librarians. There has been extremely little written about reference theory. The literature reflects more smoke than fire. Because of this presumable unconcern for theory, along with the fact that the referral process is taken for granted, a theoretical basis for reference service has changed relatively little from the latter part of the nineteenth century. What was offered at that time, purporting to be theory, was no more than a pseudo-theory-actually pseudo-theories. One does not have to look for a theory with the importance of $E=m c^{2}$. No theory was offered that suggested a conceptual basis for reference service. Such men as Samuel S. Green, William Warner Bishop, Pierce Butler and James Wyer, identified and

Mr. Vavrek is an Instructor in the Graduate School of Library and Information Sciences at the University of Pittsburgh. quantified that thing they called reference service. ${ }^{1}$ Even judging by contemporary standards and allowing for the emergence of this new activity called reference service, they did no more than define the service. It may have been a revolutionary idea to suggest that here was a service to aid the researcher with his research. But this produced little enlightenment relating to its theoretical basis. The definitions, and they must be considered in this category, were preoccupied with how much service should be given. After identifying the reference activity as aid given to a reader, it was then important to suggest variations on this theme, e.g., that it was not performing the reader's own task. It was either simply to be a gentle pat on the back or whatever. This was the thinking and concern. It is logical, therefore, that what was identified as theories of reference service came out as: maximum, minimum, and moderate. Again, one can observe that these were attempts at quantification. Maximum service related to the situation when the reference librarian performed the work for the reader. The

\footnotetext{
1 Readers interested in an excellent account of the history of reference theory are referred to Samuel Rothstein, The Development of Reference Services Through Academic Traditions, Public Library Practice and Special Librarianship (ACRL Monograph, no. 14 [Chicago: ALA, Association of College and Research Libraries, 1955]).
} 508 / 
minimum theory was used to suggest a situation where the library was acknowledged as directly performing the teaching function. The reader was obliged to do the work for himself. The moderate theory, one that can only be dubiously defined and one which this author admits he has never really understood, is supposed to refer to that service obviously falling in between maximum and minimum. This is the theory that permits confusion over when minimum theory becomes maximum. It has been suggested that under this theory the librarian was in a quandary over how much service was enough. Indeed!

These then are the so-called reference theories. They are entirely inadequate. One should not be tempted, however, to assume that the issue is really a semantic one. One will concede the ambiguity over such terms as theory and concept, but the problem lies more basically with a lack of development in this aspect of reference librarianship.

Reference service, which is largely a twentieth-century phenomenon, has existed without any theoretical basis from its inception. One hopes it is not too iconoclastic to suggest that the great names in the history of reference service did relatively little to provide such a basis. Even Pierce Butler in his Reference Function of the Library did little. He largely reiterated the status quo. He did not expand the framework any more than did his predecessors. It has already been stated that there is little in the way of published literature on this subject. The topic reference theory is one of those that contributors to the literature toss in with a multitude of other mea culpas.

The title of this paper implies that the author wishes to suggest an alternative to the pseudo-theories of reference which have so far been offered. A definition for the word "theory" has so far been begged. A relatively standard one, however, is a hypothesis suggested as a basis for thought on a topic. It is hoped that the following discussion will provide such a basis.

A statement closely resembling a theory was initially stated by Alan Rees at the Columbia Conference on Reference Service. ${ }^{2}$ His view was that reference service embodies all those variables existing between the reader and the information. This was one of the most important, but only slightly regarded, views given at the Conference. The present author has reiterated this viewpoint in other articles but as a definition for reference service. Indeed, this is the manner in which it was offered by Rees. The temptation is strong to follow past history. But this viewpoint is not simply one of many definitions that is suggested as an explanation for that phenomenon we identify as reference service. It provides a continuum. Whether or not this is testable as a hypothesis is another matter.

This is a far-reaching statement and perhaps defies contradiction because of the scope of its implications. It is not the easiest to understand; but it is not an attempt at hyperbole to give it a mantle of vagueness, and then because it is difficult to understand pass it off as theory. Many students remain perplexed by this view of reference service. What does it mean? It suggests that the entire gamut of activities which directly or indirectly affect the library must be considered as variables in the reference process. Every individual, professional as well as nonprofessional, must be considered a part of the referral process. The acquisition and cataloging of books, the circulation routines, the administrative supervision,

\footnotetext{
${ }^{2}$ Individuals interested in a report of the Conference are referred to: Winifred B. Linderman, ed. The Present Status and Future Prospects of Reference Information Service. Proceedings of the Conference Held at the School of Library Service, Columbia University, March 30-April 1, 1966 (Chicago: ALA, 1967).
} 
even the upkeep of the physical plantthese are all a part of the reference process. They all must be considered as elements, therefore, in a theory of reference. These are the variables that exist between the reader and the information. Each has the potential ability to affect the extent to which a user does or does not retrieve his information.

But what consequence does this avenue of thought provoke? Initially, it suggests that a true evaluation of a reference department's effectiveness cannot be accomplished by interpolating quantitative variables such as how many questions are asked in one subject field or what sex the individual was who asked the question. It must be the total library that is evaluated. The suggestion is not, however, that janitorial service has to be included. Obviously, attention must center around those activities which directly contribute to the flow of information in the library. The focus cannot be a department where those activities designated as reference take place. Reference service must be judged vis-à-vis the total library. Reference is the library. Even if the now phantom standards for the reference activity are eventually offered, implementation will fall miserably short if the impact of the total library is not considered in the evaluation.

Second, reference service is too often viewed by reference librarians as a game of hide-and-seek. This tendency appears also in the training of reference librarians. Even allowing for the practical basis of reference work, one should not view it as an unending dialogue of reference resources. It is so much more. A "walking Winchell" approach may be impressive, but it is decidedly less if the context is not the total library.

Third, another popular subject among contributors to library literature is the instructional function of the reference department. A reference department is charged with more than finding answers to urgent questions in appropriate books. The service falls short of its capacity when the reference librarian neglects or refuses to extend a device for self-education to the user. That device is the total library. If the library is to reach out to the public, the concept of reference service as use of the entire library must be understood and translated into meaningful service.

One may conclude after reading the preceding discussion that no theory has been advanced. To suggest that reference is all of the variables between the information and reader may prove too much to swallow. If this idea is untenable it may at least provide a basis for further refinement. The central theme, however, is sound. No workable reference theory can be developed if the context is a unidimensional continuum. The referral process is infinitely more complicated than we care to believe. It is not a group of books. It is not simply the librarian. It is not the patron, or the physical library. It is all of these.

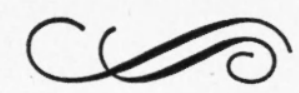

